\title{
Mildly anaemic toddlers respond to iron
}

\author{
Y A PARKS, ${ }^{*}$ M A AUKETT,* J A MURRAY, $\dagger$ P H SCOTT, $\ddagger$ AND B A WHARTON* \\ *Sorrento Maternity Hospital and Departments of †Haematology and $\ddagger$ Biochemistry, Selly Oak Hospital, \\ Birmingham
}

SUMMARY Thirty eight children with a haemoglobin concentration of $106-110 \mathrm{~g} / \mathrm{l}$ were given either oral iron $(n=17)$ or placebo $(n=21)$ for two months. The treated group achieved a significantly higher rise in haemoglobin concentration; in a quarter it was greater than $20 \mathrm{~g} / \mathrm{l}$. While those with the lower mean corpuscular volume and ferritin showed greater rises in haemoglobin these indices were of little value in predicting response in an individual child.

The definition of a normal haemoglobin concentration varies. It can be defined statistically as the mean plus or minus 2 standard deviations (SD), but the reference population studied may well include iron deficient children. Using these criteria a lower limit of normality is often set at $110 \mathrm{~g} / 1 .{ }^{12}$ Alternatively the positive response (a rise in haemoglobin of $\geqslant 10 \mathrm{~g} / \mathrm{l}^{3}$ to a therapeutic trial of iron may be used to define iron deficiency anaemia. Other authors use a haemoglobin concentration less than $105 \mathrm{~g} / \mathrm{l}$ as an indication for iron treatment. ${ }^{45}$

There exists therefore a group of children with haemoglobin concentrations of 106-110 g/l about whom opinions vary. Are children in this group anaemic and in need of iron treatment or can additional investigations define those in need of iron? A response to iron treatment is the 'gold standard' indicator of iron deficiency and it has been used in this investigation.

\section{Subjects and methods}

In a previous study we identified a group of 17-19 month old toddlers with a haemoglobin of $110 \mathrm{~g} / \mathrm{l}$ or less (97 infants, $26 \%$ of screened population). ${ }^{6}$ These anaemic children were randomly allocated to receive $10 \mathrm{ml}$ of a mixture providing either $24 \mathrm{mg}$ iron (as ferrous sulphate) plus $10 \mathrm{mg}$ vitamin $\mathrm{C}$ daily or $10 \mathrm{mg}$ vitamin $\mathrm{C}$ alone daily. Allocation was double blind using consecutively numbered bottles. After two months the children were reassessed.

Within this group of anaemic children 38 had a haemoglobin of 106-110 g/l. We have further analysed the results of other measurements of iron deficiency, and the response to iron in this group, because they are those children in whom the diagnosis of anaemia and iron deficiency is controversial. Seventeen children (12 boys and five girls, 15 Asians) received iron plus vitamin $C$, and 21 children (12 boys and nine girls, 19 Asians) received vitamin $\mathrm{C}$ alone. The social and anthropometric details of the two groups were similar.

The haematological and biochemical methods used were those described previously. ${ }^{6}$ Thalassaemia was excluded by haemoglobin A2 and F determinations. Statistical analysis was by Fisher's exact test, Pearsons coefficient of correlation, and the paired $t$ test as appropriate.

\section{Results}

EFFECT OF TREATMENT ON HAEMATOLOGICAL

MEASUREMENTS (TABLE)

The mean rise in haemoglobin concentration in the treatment group was significantly higher than in the placebo group $(17.7 \mathrm{~g} / 1$ compared with $3.2 \mathrm{~g} / \mathrm{l}$, $\mathrm{p}<0.001)$. The increase in haemoglobin was signifi-

Table 1 Haematological values before and after treatment (mean (SD))

\begin{tabular}{|c|c|c|c|c|}
\hline \multirow[b]{4}{*}{ Haemoglobin $(\mathrm{g} / \mathrm{l})$} & \multicolumn{4}{|l|}{ Group } \\
\hline & \multicolumn{2}{|c|}{ Iron plus vitamin $C(n=17)$} & \multicolumn{2}{|c|}{ Vitamin $C$ alone $(n=21)$} \\
\hline & Before & After & Before & After \\
\hline & $108 \quad(1 \cdot 0)$ & $126 \quad 6 \cdot 0)^{* * *}$ & $108 \quad(1 \cdot 0)$ & $111 \quad(8 \cdot 0)$ \\
\hline Mean corpuscular volume (fl) & $64.8(5.4)$ & $69.3(3.9)^{* * *}$ & $64 \cdot 0(5 \cdot 8)$ & $64.8(6 \cdot 6)$ \\
\hline Mean corpuscular haemoglobin (pg) & $21 \cdot 3(2 \cdot 0)$ & $23 \cdot 1(1.9)^{* * *}$ & $21 \cdot 0(2 \cdot 3)$ & $21 \cdot 3(2 \cdot 5)$ \\
\hline Serum iron $(\mu \mathrm{mol} / \mathrm{l})$ & $10.4(5.4)$ & $15 \cdot 7(8 \cdot 2)$ & $10 \cdot 0(4 \cdot 6)$ & $9 \cdot 7(4 \cdot 3)$ \\
\hline Transferrin saturation (\%) & $8.7(4 \cdot 8)$ & $16 \cdot 8(10 \cdot 4)^{*}$ & $9 \cdot 2(7 \cdot 7)$ & $10 \cdot 1(11 \cdot 7)$ \\
\hline Ferritin $(\mu \mathrm{g} / \mathrm{l})$ & $8 \cdot 3(4 \cdot 8)$ & $14.8(9 \cdot 5)^{* *}$ & $9 \cdot 2(4 \cdot 6)$ & $9.9(5 \cdot 5)$ \\
\hline
\end{tabular}

Significant rise with treatment: ${ }^{*} \mathrm{p}<0 \cdot 02,{ }^{* *} \mathrm{p}<0 \cdot 01,{ }^{* * *} \mathrm{p}<0 \cdot 001$ by paired $t$ test. 
cantly correlated with the increase in mean corpuscular volume $(r=0.69, p<0.01)$, mean corpuscular haemoglobin $(\mathrm{r}=0.64, \mathrm{p}<0.01)$, transferrin saturation $(r=0.53, p<0.05)$, but not with change in iron $(\mathrm{r}=0.45, \quad \mathrm{p}=0.09)$ and ferritin concentrations $(r=-0.12, p=0.68)$. All except one child in the treatment group achieved a haemoglobin rise of $10 \mathrm{~g} / \mathrm{l}$ or more (that is, a significant rise according to criteria of Dallman et $\mathrm{al}^{3}$ ) compared with only five of the placebo group $(\mathrm{p}<0 \cdot 01)$.

\section{PREDICTION OF RESPONSE TO IRON}

This was examined in two ways: (1) the rise in haemoglobin was negatively correlated with the original haemoglobin concentration $(r=-0.59$, $\mathrm{p}<0.02)$, mean corpuscular volume $(\mathrm{r}=-0.48$, $\mathrm{p}<0.05)$, and ferritin concentration $(\mathrm{r}=-0.51$, $\mathrm{p}<0.05)$. The rise was not related to the original iron or mean corpuscular haemoglobin concentrations or the transferrin saturation. (2) Although a haemoglobin rise of more than $10 \mathrm{~g} / 1$ has been accepted as a significant rise ${ }^{3}$ we looked for a more stringent criterion. One child in the placebo group had a haemoglobin rise as high as $21 \mathrm{~g} / 1$, which could be regarded as the maximum possible change without treatment, four $(24 \%)$ of the treated children
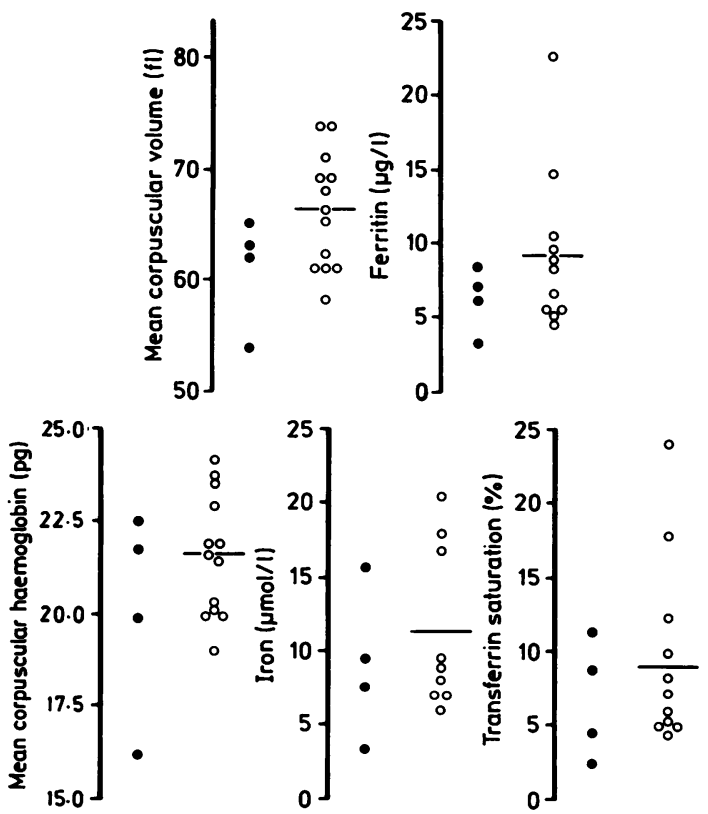

Figure Comparison of haematological indices in subjects who responded to treatment with iron (O) with a rise in haemoglobin concentration of $>21$ g/l and those who had a limited response $(O)$ with a rise in haemoglobin concentration of $\leqslant 21 \mathrm{~g} / \mathrm{l}$. achieved a haemoglobin rise greater than $21 \mathrm{~g} / 1$ $(p=0.03$ Fisher's exact test). These four children could therefore be defined as responders and the remaining 13 as limited responders. Comparison of the other haematological indices (figure) was not helpful in predicting response in an individual child. The responders all had a mean corpuscular volume and a ferritin concentration less than the means for limited responders.

\section{Discussion}

In this study we have shown that even if a child's haemoglobin concentration is $106-110 \mathrm{~g} / \mathrm{l}$ treatment results in a substantial rise in mean haemoglobin. All except one child showed a rise of $>10 \mathrm{~g} / 1$ and even using the more stringent criterion of a rise of $>21 \mathrm{~g} / 1,24 \%$ of the group showed this response. We have shown previously that a rise of $20 \mathrm{~g} / \mathrm{l}$ is associated with a significant improvement in psychomotor development. ${ }^{6}$

Although overall the children with low original values for mean corpuscular volume and ferritin concentration showed the larger rises in haemoglobin, consideration of these measurements was of little value in predicting response to iron in an individual child.

Therefore in our opinion unless there is a clear contraindication or a clear suspicion of some other cause of the anaemia-for example, macrocytosis or polychromasia - all these children should be treated and their response monitored. It may be that some children with a haemoglobin concentration greater than $110 \mathrm{~g} / \mathrm{l}$ would also show a rise in haemoglobin after iron treatment despite their not being anaemic according to the criteria of the World Health Organisation, ${ }^{2}$ but this possibility was not examined in this paper.

References

1 Dallman PR, Siimes MA. Percentile curves for haemoglobin and red cell volume in infancy and childhood. $J$ Pediatr 1979;94: 26-31.

${ }^{2}$ World Health Organisation. Nutritional anaemias. WHO Tech Rep Ser 1972:No 503.

${ }^{3}$ Dallman PR, Reeves JD, Driggers DA, Lo EYT. Diagnosis of iron deficiency: the limitations of laboratory tests in predicting response to iron treatment in 1 year old infants. $J$ Pediatr 1981; 98:376-81.

${ }^{4}$ Lozoff B, Brittenham GM, Viteri FE, Wold AW, Urrutia JJ. The effects of short term iron therapy on developmental deficits in iron deficient anemic infants. $J$ Pediatr 1982;100:351-7.

5 Oski FA, Honig AS. The effects of therapy on developmental scores of iron deficient infants. J Pediatr 1978;92:21-5.

6 Aukett MA, Parks YA, Scott PH, Wharton BA. Treatment with iron increases weight gain and psychomotor development. Arch Dis Child 1986;61:849-57.

Correspondence to Dr Y A Parks, Community Health, 41 Old Dover Road, Canterbury, Kent CT1 $3 \mathrm{HJ}$.

Accepted 21 September 1988 